\title{
PENTINGNYA DOKUMENTASI YANG DILAKUKAN PERAWAT SEBAGAI BUKTI TINDAKAN YANG DILAKUKAN
}

\author{
Rizka Safitri Siregar/181101041 \\ rizkasafitri223@gmai.com
}

\begin{abstract}
ABSTRAK
Dokumentasi asuhan kepepawatan merupakan bagian yangtidak terpisahkan dari asuhan keperawatan yang dilaksanakan sesuai standar. Pemahaman dan ketrampilan dalam menerapkan standar dengan baik merupakan suatu keharusan bagi tenaga keperawatan agar mampu melakukan pendokumentasian asuhan keperawatan secara baik dan benar. Dokumentasi keperawatan yang lengkap dan akurat akan memudahkan disiplin ilmu lain untuk menggunakan informasi di dalamnya. Dokumentasi diperlukan untuk memudahkan alur dan koordinasi dalam perawatan pasien. Tujuannya adalah agar pendokumentasian di rumah sakit dilaksanakan dengan baik dan benar. Metode yang digunaka adalah metode kualitatif dimana maksudnya dengan cara mengumpulkan sebanyak-banyaknya data untuk dianalisis. Yaitu dengan Literature review ini dengan menganalisis yang berfokus pada prinsip-prinsip pendokumentasian asuhan keperawatan. Adapun tinjauan literatur yang digunakan seperti buku teks, bukureferensi, jurnal, dan google scholar. Dengan kata kunci prinsip, pendokumentasian, asuhan keperawatan .Dan yang digunakan adalah 14 literatur yang diterbitkan 10 tahun terakhir.
\end{abstract}

Kata Kunci : Prinsip, Pendokumentasian, Asuhan Keperawatan.

\section{PENDAHULUAN}

Dokumentasi keperawatan merupakan salah satu fungsi yang paling penting dari perawat sejak zaman Florence Nightingle karena berfungsi ganda dan beragam tujuan. Saat ini sistem pelayanan kesehatan memerlukan dokumentasi yang menjamin kesinambungan perawatan, melengkapi bukti hukum, proses keperawatan dan mendukung kualitas perawatan pasien. Saat ini masalah yang paling menantang dalam keperawatan adalah bagaimana untuk mendokumentasikan perawatan pasien yang berkualitas dengan berbagai kendala yang berkenaan dengan peraturan hukum. Untuk melindungi tenaga perawat akan adanya tuntutan dari klien/pasien perlu ditetapkan dengan jelas apa hak, kewajiban serta kewenangan perawat agar tidak terjadi kesalahan dalam melakukan tugasnya serta 
memberikan suatu kepastian hukum, perlindungan tenaga perawat. Hak dan kewajiban perawat ditentukan dalam Kepmenkes 1239/2001 dan Keputusan Direktur Jenderal Pelayanan Medik Nomor Y.M.00.03.2.6.956 (Kepmenkes, 2001). Berhubungan dengan pasal 63 ayat 4 UU no 36/2009 berbunyi "Pelaksanaan pengobatan dan/atau perawatan berdasarkan ilmu kedokteran atau ilmu keperawatan hanya dapat dilakukan oleh tenaga kesehatan yang mempunyai keahlian dan kewenangan untuk itu". Yang mana berdasarkan pasal ini keperawatan merupakan salah satu profesi/tenaga kesehatan yang bertugas untuk memberikan pelayanan kepada pasien yang membuthkan. Berdasarkan undang-undang kesehatan yang diturunkan dalam Kepmenkes 1239 dan Permenkes No. HK.02.02/Menkes/148/I/2010, terdapat beberapa hal yang berhubungan dengan kegiatan keperawatan. Ditemukan di rumah sakit dokumentasi keperawatan tidak lengkap dengan beberapa alasan seperti motivasi perawat kurang karena banyak kegiatan yang menjadi beban, tidak semua perawat di institusi pelayanan memiliki pengetahuan dan kemampuan yang sama, tenaga keperawatan berasal dari jenjang pendidikan yang berbeda.

\section{TUJUAN}

Tujuan dari kajian ini adalah Mengidentifikasi status kesehatan klien dalam rangka, mencatat kebutuhan klien, merencanakan, melaksanakan tindakan keperawatan, dan mengevaluasi tindakan. Dokumentasi untuk penelitian, keuangan, hukum dan etika.

\section{METODE}

Metode yang digunakan adalah metode kualitatif dimana maksudnya dengan cara mengumpulkan sebanyak-banyaknya data untuk dianalisis. Yaitu dengan Literature review ini dengan menganalisis yang berfokus pada Model dan teknik-teknik pendokumentasian dalam asuhan keperawatan. Adapun tinjauan literatur yang digunakan seperti buku teks, buku referensi, jurnal, dan google scholar. Dengan kata kunci Model pendokumentasian, Teknik Pendokumentasian, Asuhan Keperawatan. Dan literature yang digunakan adalah 14 literatur yang diterbitkan 10 tahun terakhir. 


\section{HASIL/PEMBAHASAN}

Dokumentasi asuhan keperawatan merupakan bagian yangtidak terpisahkan dari asuhan keperawatan yang dilaksanakan sesuai standar. Pemahaman dan ketrampilan dalam menerapkan standar dengan baik merupakan suatu keharusan bagi tenaga keperawatan agar mampu melakukan pendokumentasian asuhan keperawatan secara baik dan benar. Dokumentasi keperawatan yang lengkap dan akurat akan memudahkan disiplin ilmu lain untuk menggunakan informasi di dalamnya. Dokumentasi diperlukan untuk memudahkan alur dan koordinasi dalam perawatan pasien (Green \& Thomas, 2008). Dokumentasi kepeawatan mempunyai 3 prinsip yaitu: Brevity, Legibility, dan Accuracy (Carpenitto, 1991). Prinsip-perinsip tersebut di atas dapat dijelaskan sebagai berikut: 1) Brevity, dalam melakukan pendokumentasian setiap petugas/perawat harus brevity, Brevity sendiri adalah ringkas, jadi kita dalam mencatat isi dokumentasi keperawatan harus ringkas dan tidak perlu memasukan kata-kata atau kalimat yang tidak penting dan mempunyai makna yang tidak sesuai. 2) Legidibility, yaitu dimana dalam penulisan/pencatatan dokumentasi keperawatan harus mudah dibaca dan di pahami oleh perawat lain atau profesi lain yang ikut dalam proses pendokumentasian. 3) Accuracy adalah sesuai dengan data yang ada pada klien. Jadi kita harus memasukan data pada dokementasi keperawatan harus benar dan sesuai dengan data baik identitas, laboratorium dan radiologi pada setiap klien. Ini adalah aspek yang sangat vital dan tidak boleh salah atau tertukar dengan klien lain. Hal yang pokok dalam prinsip-prinsip dokumentasi adalah :

1. Dokumentasi harus dilakukan segera setelah pengkajian pertama dilakukan, demikian juga pada setiap langkah kegiatan keperawatan.

2. Bila memungkinkan, catat setiap respon pasien / keluarganya tentang informasi / data yang penting tentang keadaannya.

3. Pastikan kebenaran setiap data data yang akan dicatat.

4. Data pasien harus objektif dan bukan merupakan penafsiran perawat, dalam hal ini perawat mencatat apa yang dilihat dari respon pasien pada saat merawat pasien mulai dari pengkajian sampai evaluasi. 
5. Dokumentasikan dengan baik apabila terjadi hal-hal sebagai berikut : adanya perubahan kondisi atau munculnya masalah baru, respon pasien terhadap bimbingan perawat.

6. Harus dihindari dokumentais yang baku sebab sifat individu /Pasien adalah unik dan setiap pasien mempunyai masalah yang berbeda.

7. Hindari penggunaan istilah penulisan yang tidak jelas dari setiap catatan yang dicatat, harus disepakati atas kebijaksanaan institut setempat.

8. Data harus ditulis secara syah dengan menggunakan tinta dan jangan menggunakan pinsil agar tidak mudah dihapus.

9. Untuk merubah atau menutupi kesalahan apabila terjadi salah tulis, coret dan diganti dengan yang benar kemudian ditanda tangani.

10. Untuk setiap kegiatan dokumentasi, cantumkan waktu tanda tangan dan nama jelas penulis.

11. Wajib membaca setiap tulisan dari anggota lain kesehatan yang lain sebelum menulis data terakhir.

12. Dokumentasi harus dibuat dengan tepat, jelas dan lengkap.

Model Pendokumentasian dalam asuhan keperawatan, antara lain :

1. Model dokumentasi SOR (source oriented record)

Model dokumentasi SOR (source-oriented-record)merupakan model dokumentasi yang berorientasi pada sumber informasi. Model ini menempatkan catatan atas dasar disiplin orang atau sumber yang mengelola pencatatan. Dokumentasi dibuat dengan cara setiap anggota tim kesehatan membuat catatan sendiri dari hasil observasi. Kemudian, semua hasil dokumentasi dikumpulkan menjadi satu. Sehingga masing-masing anggota tim kesehatan melaksanakan kegiatan sendiri tanpa bergantung dengan anggota tim kesehatan yang lain. Misalnya, kumpulan dokumentasi yang bersumber dari dokter, bidan, perawat, fisioterapi, ahli gizi, dan lain-lain.Dokter menggunakan lembar untuk mencatat instruksi, lembaran riwayat penyakit dan perkembangan penyakit. Bidan menggunakan catatankebidanan, begitu pula disiplin lain mempunyai catatan masing-masing.Model ini dapat diterapkan 
pada pasien rawat inap, yang didalamnya terdapat catatan pesan Dokter yang ditulis oleh Dokter, dan riwayat keperawatan yang ditulis oleh perawat. Namun demikian, secara umum catatan ini berupa pesan Dokter. Catatan-catatan dalam model ini ditempatkan atas dasar disiplin orang atau sumber yang mengolah pendokumetasian. Model dokumentasi SOR ini dapat dibuat dengan formulir grafik, format pemberian obat, format catatan perawat termasuk riwayat penyakit klien, riwayat perawatan perawatan dan perkembangan pasien, pemeriksaan laboratorium dan pemeriksaan diagnostik, formulir masuk Rumah sakit dan formulir untuk tindakan operasi yang ditandatangani oleh pasien dan keluarga. Model dokumentasi SOR terdiri dari 5 kompnen, yaitu: Lembar penerimaan berisi biodata, Lembar instruksi Dokter, Lembar riwayat medis atau penyakit, Catatan perawat. dan Catatan dan laporan khusus. Keuntungan model dokumentasi SOR (source-orientedrecord)adalah: Menyajikan data yang berurutan dan mudah diidentifikasi, Memudahkan perawat melakukan cara pendokumentasian, Proses pendokumentasian menjadi sederhana.

\section{Model dokumentasi POR (Problem-oriented-record)}

Model dokumentasi POR (problem-oriented-record) merupakan model dokumentasi yang berorientasi pada masalah. Dimana model ini berpusat pada data klien yang didokumentasikan dan disusun menurut masalah klien. Pendekatan ini pertama kali dikenalkan oleh dr. Lawrence Weed dari Amerika Serikat. Dalam format aslinya pendekatan berorientasi masalah ini dibuat untuk memudahkan pendokumentasian dengan catatan perkembangan yang terintegrasi, dengan sistem ini semua petugas kesehatan mencatat observasinya dari suatu daftar masalah. Komponen-komponen model dokumentasi POR :

a. Data dasar merupakan kumpulan informasi tentang klien yang berisi semua informasiinformasi yang telah dikaji dari klien sejak pertama kali masuk Rumah Sakit. Data dasar ini meliputi: riwayat klien tentang keadaan umum klien, riwayat keluarga, keadaan penyakit yang dialami pasien, tindakan keperawatan yang pernah diberikan, pemeriksaan fisik, dan data-data penunjang (laboratorium dan diagnostik). 
b. Daftar masalah merupakan hasil penafsiran dari data dasar atau hasil analisis dari perubahan data. Daftar ini mencerminkan keadaan atau nilai yang tidak normal dari data yang didapat dengan menggunakan urutan prioritas yang dituliskan ke dalam daftar masalah dan diberikan pada setiap pergantian shift. Kriteria daftar masalah yang dibuat adalah: Data yang telah teridentifikasi dari data dasar disusun sesuai dengan tanggal identifikasi masalah, Daftar masalah ditulis pertama kali oleh perawat yang pertama kali bertemu dengan klien ataupun orang yang diberi tanggungjawab untuk menuliskannya, Daftar ini berada pada bagian depan status klien, Tiap masalah diberikan tanggal, nomor, rumusan masalah, serta nama perawat yang menemukan masalah tersebut.

c. Daftar rencana awal asuhan keperawatan merupakan rencana yang dapat dikembangkan secara spesifik untuk setiap masalah. Daftar rencana awal asuhan keperawatan terdiri dari tiga komponen, yaitu: Pemeriksaan diagnostic, Manajemen kasus atau disebut juga usulan terapi, dan Pendidikan kesehatan (sebagai tujuan jangka panjang).

d. Catatan perkembangan merupakan catatan tentang perkembangan dari keadaan klien yang didasarkan pada setiap masalah yang ditemukan pada klien. Revisi atau pembaharuan rencana dan tindakan mengikuti perubahan dari keadaan klien. Catatan perkembangan ini berisi perkembangan atau kemajuan dari setiap masalah kesehatan klien. Catatan perkembangan dapat digunakan dalam bentuk: SOAP, SOAPIER, dan PIE.

3. Model dokumentasi POR (progress-oriented-record)

Model dokumentasi POR (progress-oriented-record) merupakan model dokumentasi yang berorientasi pada perkembangan dan kemajuan klien. jenis-jenis catatan yang dapat digunakan dalam model keperawatan POR (progress-oriented-record) yaitu: Catatan perawatan biasanya ditulis tiap 24 jam, lembar alur, Catatan pemulangan dan ringkasan rujukan

\section{Model dokumentasi CBE (charting by exeption)}

Model dokumentasi CBE (charting by exeption) adalah sistem dokumentasi yang hanya mencatat hasil atau penemuan yang menyimpang dari keadaan normal tubuh. 
Penyimpangan yang dimaksud dalam hal ini menyangkut keadaan yagn tidak sehat yang menganggu kesehatan klien. Komponen Model dokumentasi CBE (charting by exeption),meliputi : Dokumentasi berupa kesimpulan dari penemuan-penemuan penting dan menjabarkan indikator pengkajian dan Dokumentasi ini dilakukan berdasarkan standart praktik keperawatan.

5. Model dokumentasi PIE (problem-intervention-evaluation)

Model dokumentasi PIE (problem-intervention-evaluation) merupakan suatu pendekatan orientasi -proses pada dokumentasi keperawatan dengan penekanan pada masalah keperawatan, intervensi dan evaluasi keperawatan. Karakteristik Model dokumentasi PIE (problem-intervention-evaluation) adalah: Dimulai dari pengkajian ketika pertama kali klien masuk ke Rumah sakit, diikuti dengan pelaksanaan pengkajian sistem tubuh pada setiap pergantian dinas, Data masalah dipergunakan untuk asuhan keperawatan dalam waktu yang lama dan juga untuk masalah yang kronis, Intervensi yang dilaksanakan dan rutin, didokumentasi dalam flow sheet, Catatan perkembangan digunakan untuk intervensi yang spesifik, Masalah yang ditemukan pada klien, dibuat dengan simbol "P (problem)", Intervensi terhadap penyelesaian masalah, biasanya dibuat dengan simbol " I (intervention)", Keadaan klien sebagai pengaruh dari intervensi, dibuat denga simbol "E (evaluation)" dan Setiap masalah yang diidentifikasi harus dievaluasi minimal 8 jam.

\section{Model dokumentasi POS (process-oriented-system)}

Model dokumentasi POS (process-oriented-system) yang disebut juga dengan model dokumentasi fokus adalah suatu model dokumentasi yang berorientasi pada proses keperawatan mulai dari pengumpulan data klien, diagnosis keperawatan (masalah yang muncul), penyebab masalah, atau definisi karakteristik yang dinyatakan sesuai dengan keadaan klien. Catatan perkembangan pada model dokumentasi Fokus ditulis dengan menggunakan format DAR, yaitu: Datum(D), yaitu : data subjektif dan data objektif, Action (A), yaitu: tindakan keperawatan yang segera atau yang akan dilakukan, dan Response (R), yaitu respon klien terhadap tindakan medis dan tindakan keperawatan yang telah diberikan kepada klien. 


\section{Sistem dokumentasi Core}

Sistem dokumentasi core merupakan sistem dokumentasi pusat yang merupakan bagian terpenting dari sistem dokumentasi dalam proses keperawatan. Catatan perkembangan pada Model Dokumentasi Core, ditulis dengan menggunakan Format DAE, yaitu: Datum (D), yaitu : data subjektif dan data objektif, Action (A), yaitu: tindakan keperawatan yang segera atau yang akan dilakukan, dan Evaluation (E) : evaluasi untuk melihat respon klien terhadap tindakan medis dan tindakan keperawatan yang telah diberikan kepada klien.

\section{KESIMPULAN}

Dokumentasi keperawatan adalah suatu catatan yang memuat seluruh informasi yang dibutuhkan untuk menentukan diagnosis keperawatan, menyusun rencana keperawatan, melaksanakan dan mengevaluasi tindakan keperawatan yang disusun secara sistematis, valid, dan dapat dipertanggungjawabkan. Model Pendokumentasian dalam asuhan keperawatan, antara lain : Model dokumentasi SOR (source oriented record), Model dokumentasi POR (Problem-oriented-record), Model dokumentasi POR (progress-orientedrecord), Model dokumentasi CBE (charting by exeption), Model dokumentasi PIE (problem-intervention-evaluation), Model dokumentasi POS (process-oriented-system), dan Sistem dokumentasi Core. Dalam pendokumentasian ada 3 teknik, yaitu : Bentuk naratif, Flowsheet (bentuk grafik), dan Checklist.

\section{REFERENSI}

Dinarti, A. (2009). Dokumentasi Keperawatan. Jakarta: Trans Info Media

Hutahaen, Serii. (2010). Konsep dan Dokumentasi Proses Keperawatan. Jakarta: Trans Info Media Jakarta

Noorkasiani, N., Gustina, R., \& Maryam, S. (2015). Faktor-Faktor yang Berhubungan dengan Kelengkapan Dokumentasi Keperawatan. Jurnal Keperawatan Indonesia, $18(1), 1-8$. 
Potter, A.P., \& Perry, G.A. (2010). Fundamental Keperawatan Buku 1 Edisi 7. Jakarta : Salemba Medika

Potter, A., \& Perry, A. (2017). Buku Ajar Fundamental Keperawatan: Konsep, Proses, dan Praktik (4th ed.). Jakarta: Buku Kedokteran EGC.

Rezkiki, F., \& Ilfa, A. (2018). Pengaruh Supervisi Terhadap Kelengkapan Dokumentasi Asuhan Keperawatan Di Ruangan Non Bedah. Real in Nursing Journal, 1(2), 6776.

Rosdahl, C. B., \& Kowalski, M. T. (2014). Buku Ajar Keperawatan Dasar. Jakarta: EGC

Serri, H. (2010). Konsep dan Dokumentasi Proses Keperawatan. Jakarta: Trans Info Medika .

Simamora, R. H. (2008). Peran Manajer Dalam Pembinaan Etika Perawat Pelaksana Dalam Peningkatan Kualitas Pelayanan Asuhan Keperawatan. IKESMA, 4(2)

Simamora, R. (2009). Dokumentasi Proses Keperawatan.

Simamora, R. (2010). Komunikasi dalam keperawatan

Siswanto, L. H., Hariyati, R. T. S., \& Sukihananto, S. (2013). Faktor-Faktor yang berhubungan dengan kelengkapan pendokumentasian asuhan keperawatan. Jurnal Keperawatan Indonesia, 16(2), 77-84.

Supratti, S., \& Ashriady, A. (2018). Pendokumentasian Standar Asuhan Keperawatan Di Rumah Sakit Umum Daerah Mamuju. Jurnal Kesehatan Manarang, 2(1), 44-51.

Wulandini, P., Krianto, T., \& Priwahyuni, Y. (2016). Faktor-Faktor yang Berhubungan Dengan Perilaku Pendokumentasian Asuhan Keperawatan di RSJ Tampan Pekanbaru Tahun 2014. NERS Jurnal Keperawatan, 12(2), 131-142. 
Yeni, F. (2014). Pengaruh Pelatihan Proses Keperawatan terhadap Dokumentasi Asuhan Keperawatan di Puskesmas Kabupaten Agam Propinsi Sumatera Barat. NERS Jurnal Keperawatan, 10(1), 24-31.

Zakiyah, A. (2015). Hubungan Sikap dan Karakteristik Perawat Dengan Pendokumentasian Asuhan Keperawatan di Rumah Sakit Umum Sidoarjo. Jurnal Keperawatan Sehat, $5(01)$. 